\title{
Community Policing and the Syrian Refugee Community in Wellington District
}

\author{
Author: Tohill, Yvette
}

To cite this article: Tohill, Y. (2021) Community Policing and the Syrian Refugee Community in Wellington District. National Security Journal, 3(1). doi: 10.36878/nsj20210302.01

To link to this article: https://doi.org/10.36878/nsj20210302.01

View CrossRef data: https://search.crossref.org/?q=10.36878\%2Fnsj20210302.01

Journal Article published 08 March 2021 in National Security Journal. 


\title{
COMMUNITY POLICING AND THE SYRIAN REFUGEE COMMUNITY IN WELLINGTON DISTRICT
}

\author{
Yvette Tohill ${ }^{1}$
}

\begin{abstract}
Relationships between the New Zealand Police and refugee communities are largely unresearched. This case study focuses on Syrian refugees in the Wellington region of New Zealand. Syrian refugees are notable by their numbers since the onset of the Syrian Civil War in 2014, and Greater Wellington is an area where many have been re-settled. Police are a key symbol of the state and interaction with police can leave defining impressions. This study researches refugee experiences in New Zealand through semi-structured interviews with police and others who have worked with Syrian refugees. It seeks to shed light on the mixed nature of the refugee experience and the opportunities for improvement that exist. Community Policing studies in New Zealand have not previously included aspects of ethnicity beyond New Zealand Maori, and this study may therefore assist in more generally understanding the strengths and challenges of Community Policing and refugee communities in New Zealand.
\end{abstract}

\section{Introduction}

New Zealand is one of less than 40 countries globally which accepts refugees. Under its Refugee Quota Programme New Zealand has previously accepted up to a thousand (recently increased to 1,500) refugees annually, the make-up varying year on year. Since 2015, refugees from Syria have made up the largest percentage of nationalities among refugees to New Zealand, and among the number of regions where people are placed, Wellington district has resettled the largest number in recent times. ${ }^{1}$ While officially New Zealand has sought to present itself as sympathetic to the plight of refugees, the Ardern Government attracted international criticism for a perceived discriminatory approach to its acceptance of refugees and New Zealander's themselves are not necessarily welcoming of them. ${ }^{2}$ In 2020 an Auckland study reported that over half of Aucklanders

$1 \quad$ Yvette Tohill is a graduate in the Master of International Security (Intelligence) programme with the Centre for Defence and Security Studies at Massey University. Yvette would like to acknowledge the supervision, support and encouragement of Dr John Battersby and thank him for his assistance in undertaking this research. Additionally, this research would not have been possible without the willingness and openness of the Refugee Support workers and Community Policing staff interviewed. Their contributions and the support of their organisations for this research is greatly appreciated. 
viewed ethnic and cultural diversity negatively, ${ }^{3}$ and a survey of New Zealanders found $21 \%$ of the sample did not believe New Zealand should accept refugees. ${ }^{4}$ Further adding to the stress of their adjustment is the impact of their previous experiences in their countries of origin, then in transition and finally being introduced to New Zealand, most likely as different as any country could be from their own. Given the on-going civil war, the largest group making up refugees coming to New Zealand are Syrian. This study focuses on this group as a case study.

The limitations of time and space have necessitated that parameters imposed on this study are strict. A key element of any state and its relationship to society is the nature of its police. New Zealand clearly aims to police by consent, its patrol constables are not routinely armed and it emphasises the importance of its relationship with communities. Therefore, this study looks at a new community - Syrian refugees in the Wellington District and how this community perceives and interacts with the police. Community Policing is an area of policing where communities will have greater opportunities for exploring meaningful relationships with police. The New Zealand Police does not appear to have its own specific definition of Community Policing, but operates with an understanding that is consistent with international approaches.

Relationships between the New Zealand Police and refugee communities are largely unexplored. In order to reference where some of the challenges may exist for these relations, it helps to examine research relating to refugee experiences in New Zealand, identifying relevant issues. Studies of different ethnic minority perceptions of the New Zealand Police are also examined to highlight areas of difference that signal opportunities for Community Policing, or gaps in knowledge across the body of research in New Zealand. Community Policing studies in New Zealand have to-date not included aspects of ethnicity beyond New Zealand Maori, therefore international examples can assist in understanding the strengths and challenges of a Community Policing approach to Police-Syrian refugee community relations.

\section{The Refugee Experience in New Zealand}

Refugee resettlement studies within New Zealand demonstrate that aspects of the resettlement experience disrupt successful integration and create conflict. Fitzgerald's (2017) study of Syrian women in New Zealand argued that satisfaction with resettlement was determined by feelings of respect, having basic needs met, and the importance of language, culture and family. A lack of respect was associated with discrimination by some, particularly in relation to the wearing of hijab. ${ }^{5}$ Issues of conflict in resettlement arose regarding separation from, and the safety of family in Syria, competing with satisfaction from attaining safety in New Zealand, and a brighter future for their children. ${ }^{6}$ This study was conducted only three years into the settlement of the initial Syrian refugee cohort in 2014, and it may be questioned if its conclusions still hold a half a decade later. 
DeSouza (2011) examined the resettlement experience of refugee women in New Zealand who came as a single parent unit. The study concluded that women on their own experienced a magnification of many of the issues encountered by refugees generally, and may benefit from a more comprehensive support system. Racism, relating to clothing and accent was experienced, both interpersonally and institutionally. Parenting challenges produced feelings of disempowerment with the intervention of government services. ${ }^{7}$ This study raises questions regarding how the New Zealand Police can best support and service refugee women.

Rose Kadri (2009) explored the journey of Arab Muslim refugees to New Zealand. Many of her conclusions echoed those of Fitzgerald's, with language barriers, unemployment, challenges with family and a reluctance to view New Zealand as a permanent home all experienced. ${ }^{8}$ Gaps existed regarding expectations and delivery for Government Housing and Employment services. Housing in areas described as "deprived", contributed to feeling unsafe. ${ }^{9}$ As the study only dealt with the agencies that are part of the resettlement process, it is not known how participants felt about other services, such as the New Zealand Police.

Elliot and Yusuf (2014) examined the experiences of Somalian refugees in New Zealand, through both interviews of refugees, and a focus group of refugee services. They argue, multiculturalism is a positive force which supports a sense of security and social cohesion. Their conclusions highlight that while positive relationships support a sense of belonging, unfriendly occurrences could also undermine integration. ${ }^{10}$ Refugee relationships with state structures can impact on perceptions of value in comparison with other groups within New Zealand society. A focus group of eight government service providers and non-government organisations in Elliot and Yusuf's study highlighted concerns over the impact of ethnic profiling by law enforcement agencies. ${ }^{11}$ It is unclear whether this opinion was formed through first-hand observations, or the reported experiences of their clients, which may or may not be subjective interpretations. Furthermore, it is uncertain whether 'law enforcement agencies' refers solely to the New Zealand Police.

Kate, Verbitsky and Wilson (2018) examined the perceptions of sources of conflict in the Auckland refugee community. Over half of the refugee community leaders interviewed reported a general fear of authority figures and the New Zealand Police in particular, from within their own communities. Sources of these feelings included the transference of fear from home country experiences, as well as the creation of misunderstandings due to language barriers. ${ }^{12}$ While this suggests these feelings are a perception only, they are likely to have a significant impact on any interactions with authority figures in New Zealand. 
Kate et al argue that many of New Zealand's conflict resolution organisations are monocultural, and not necessarily suitable or understood by many refugee communities. ${ }^{13}$ Communication issues, service access and a lack of interpreters caused conflict. Police involvement stalled the ability to utilise traditional cultural ways of conflict resolution, therefore Ethnic Liaison Officers were used as a last resort. ${ }^{14}$ New Zealand justice initiatives incorporating indigenous perspectives were emerging, but were yet to recognise the value of refugee community methods. ${ }^{15}$ Information about services specific to Refugee needs, earlier intervention, greater cultural awareness and refugeespecific training of government services was necessary. ${ }^{16}$ Community policing recommendations included increases of Ethnic Liaison Officers and ethnic youth programs supporting integration through self-esteem. ${ }^{17}$ It is worth exploring whether there are regional differences in these findings, and opportunities for Community Policing beyond these recommendations.

Jaegar and Vitalis (2005) studied the ethnic diversity of officers in the New Zealand Police, identifying that officers recognised greater responsiveness was needed by the organisation to meet the requirements of ethnic communities. They argue that policing in a multicultural society demanded greater discretion and flexibility for individual officers regarding decision-making. ${ }^{18}$ Additionally, they contended that addressing communities' security and policing concerns supported harmonious Police-community relationships. ${ }^{19}$ Community Police officer perceptions may provide a more in depth understanding of the current environment, the use of alternative resolutions and the challenges facing refugee communities.

\section{Ethnic Perceptions of the New Zealand Police}

Research exploring the perceptions of ethnic groups about the New Zealand Police is limited although two studies provide some relevance. Ho, Cooper and Rauschmayer (2006) looked at various ethnicities' perceptions of the New Zealand Police, and Nisar (2013) specifically looked at South Asian perceptions. Challenges with speaking English, reporting incidents and accessing services were described as major barriers for minority groups. ${ }^{20}$ Even with English proficiency, communication with police was still described as a problem in need of improvement due to misunderstandings and a lack of refugee specific knowledge. ${ }^{21}$ Ho et al, assert that negative pre-migration experiences influenced some migrants and refugees to fear police in New Zealand, and were unable to obtain participation in their study from some members of refugee communities, particularly Middle Eastern due to this reason..$^{22}$ These findings warrant a deeper look at how the New Zealand Police are perceived among ethnic communities, and to what extent Community Police, utilising non-crime opportunities, have influenced this perception. 
Age is an influential factor in the perceptions of Police. International literature has found ethnic minority youth often hold negative perceptions regarding police in host countries. ${ }^{23}$ There is some indication of this emerging among groups of ethnic minority youth in New Zealand. ${ }^{24}$ Nakhid's (2017) study identified negative perceptions of New Zealand Police were present among African youths, and Ho et al, maintain that youth of Vietnamese backgrounds were reluctant to report crimes to police due to a perception that Police could not keep them safe from retribution. ${ }^{25}$

Negative perceptions of the New Zealand Police found by Ho et al, were due to feelings of prejudice and bias, insensitivity and a failure to listen. ${ }^{26}$ Dissatisfaction related to the response and resolution of crime, a general lack of contact and visibility of police in the community, and a particular focus on traffic policing. ${ }^{27}$ Concerns have been raised regarding a lack of cultural understanding and training, in the New Zealand Police, as well as government services generally. ${ }^{28}$ Participants were not aware of the specific support police offered for those of different ethnicities, such as Ethnic Liaison Officers. ${ }^{29}$ Whether this signals a lack of numbers, information or visibility of these officers within communities is worth further exploration. This demonstrates how an individuals' personal experiences can influence generalisations across services, and potentially how language and accessibility barriers contribute to alienation of minority groups. ${ }^{30}$

\section{Community Policing Research}

While New Zealand research is lacking, overseas research ably debates the opportunities and challenges for Community Policing operators to build effective relationships with refugees and ethnic minorities to support positive integration experiences. Significantly, it has been observed that police management need to demonstrate more than 'intellectual commitment' to ensure success and address gaps in implementation. ${ }^{31}$ Canada, is an example of a state supportive of multiculturalism, with an intake of Syrian refugees in the thousands, which has had both successes and failures in its Community Policing approach. Early efforts resulted in the over-policing of immigrants, and militarised strategies. ${ }^{32}$ Current practices are criticised due to an inability to recognise the impact that the power imbalance has in reinforcing cultural inequality, ${ }^{33}$ assumptions that utilising officers of colour alone is sufficient, failure to incorporate civilian representation, and consultative fatigue. ${ }^{34}$

Mastrofski (2019) argues that well implemented Community Policing is hard to achieve, and even mixed results are noteworthy. ${ }^{35}$ Police reforms in Toronto and Ottawa have both utilised minority group input in construction of policy and implementation to address concerns regarding over and under-policing of minority groups. ${ }^{36}$ Community policing can increase public support of police, improve police effectiveness, and contribute to positive rebuilding of vulnerable neighbourhoods. ${ }^{37}$ 
Garth den Heyer (2019) studied the role of New Zealand Police Cultural Liaison Officers in regards to crime prevention and Community Policing. Fifty officers were contacted, covering Maori, Pacific and Ethnic liaison roles. Those who responded (13 Maori and one Pacific Liaison officer) limit the generalisation of the results to other ethnicities supported. Findings that support Community Policing include prioritising community gatherings, facilitating communication and building trust. Heyer asserts Police-ethnic community relationships still require work and recommends more Ethnic Liaison Officers. Furthermore, he notes these roles lack formal training or on-going education to support relationship building with communities, ${ }^{38}$ a situation which may potentially exist across many Community Policing roles.

This study addresses some of the gaps identified in research to date, while providing further knowledge to support greater understanding of the most significant challenges facing the New Zealand Police and its Community Police in building effective relationships and support for the Syrian Refugee Community in Wellington District.

\section{Methodology}

This research used a semi-structured interview style with six participants who were involved in the resettlement process of Syrian Refugees in Wellington District. This allowed the focused exploration of some consistent topics, such as challenges, experiences with Police or the Syrian refugee community, future risks, opportunities, necessary considerations for successful programs, training for Police and current initiatives. Some questions were provided prior to interviews, to introduce the topics and allow for preparation. During the interview, follow up questions further explored experiences and participants' thinking. Participants were encouraged to highlight anything they considered particularly relevant to the research.

Interviews took place at locations where the participants were most comfortable, and ranged from participants' homes, to offices. The audio recordings were transcribed. ${ }^{39}$ The analysis contained in this research report was based on the written transcriptions. Where further information was sought post-interview, questions were emailed to the participants.

Privacy was a significant concern due to the vulnerabilities of refugees and their experiences. The questions were designed to elicit general trend information, such as the types of crimes or interactions with Police that had been experienced, and the activities, or opportunities that might exist to better support feelings of safety and wellbeing in this community. Identifying information was not sought, and where experiences referred to may have identified individuals, names or references were removed to maintain privacy. The naming protocols of the transcripts protected the privacy of participants, utilising a unique number rather than names. 
Participants were selected from two distinct groups, refugee support workers in Wellington district who had experience with resettling the Syrian refugee community, and New Zealand Police officers from Wellington district who worked in Community Policing fields. By interviewing two distinct groups it was hoped to obtain a more complete understanding of the challenges and opportunities, with commonalities between each group identified, and highlighting aspects of significance to either the Syrian refugee community, or local Community Police.

Selective participation was undertaken in order to get the most experienced individuals. An approach was made to the head of the Wellington refugee resettlement service, and consultation took place around the project and the use of refugee support workers for participation, resulting in the selection of two participants. A further individual who was a former support worker, and of Syrian origins, was also approached to participate. These individuals had a mixture of ethnicity, with Syrian, Iraqi and New Zealand European backgrounds. In two of the three cases they had social work background, and a migrant experience of their own. Two of the three participants also had supported the Syrian refugee community in Wellington district since the first resettlement, some six years earlier, and provide ongoing support to many.

The three Police participants were selected by identifying officers with relevant experiences. All Police participants had significant policing experience, and two had been in their current roles for several years. Participants came from School Community, Ethnic Liaison and Community Constable Roles. Geographic work locations also differed across Wellington district.

Completed transcriptions were analysed for themes relating to identified challenges and opportunities from both groups. Sections of the transcription relating to the themes identified were highlighted as codes using the qualitative analytical software program, Nvivo. The program collates information according to codes identified, providing summaries of codes and the percentage of coverage of the particular theme across the transcribed material. This identifies the strongest themes, and provides easily retrievable theme data.

This study chose to seek the perspective of support workers who assist the Syrian refugee community in Wellington, rather than Syrian refugees themselves. This choice was based on the exploratory nature of the study, which utilised a small sample size. In considering the right support for Syria refugees it was assessed that interviewing support workers who had multiple experiences to inform their thinking would collect the most usable data, minimise the impact that individual experiences would have had on the findings, and that questioning would not instigate fear of authority or a desire to please. 


\section{Findings and Discussion}

\section{Communication}

Communication was one of the biggest challenges for the Syrian refugee community in their resettlement. Support workers stated that Syrian refugees often arrive in New Zealand with very little English and improvements take many years. There is a particular danger in assumptions by Police that some grasp of English means that understanding has taken place. As Participant One notes:

many Police officers, when they see clients speaking broken English, they have a little bit of English, they will go with it. I can guarantee that that client is understanding only maybe $20 \%$ of what is being said to them, and saying "yes, yes, yes" to what has been said to them.

The challenges with attaining English proficiency also highlight the potential for Syrian refugees to delay contact with Police, or simply not call at all, an experience shared by ethnic communities in general. ${ }^{40}$ Refugees who enter New Zealand under the Quota system will still be seriously challenged in their efforts to communicate in English well beyond the twelve months that support is provided. Additionally, reported contact between ethnic communities the New Zealand Police by Ho et al was low, ${ }^{41}$ suggesting the presence of unreported crime.

Using friends, family, or interpreting services to translate can ensure greater communication and understanding, however this study identifies challenges that may be cause for concern or misinterpretation. Both Participants' Three and Six spoke about using children as interpreters. Some children, through a quicker grasp of English fall into the role of interpreter for the family. Negative impacts can occur in parent-child power dynamics, exposure of children to sensitive issues and responsibilities beyond their years, ${ }^{42}$ embarrassment by parents, ${ }^{43}$ and misinterpretation, as a child's understanding of the meaning of words may alter the messages conveyed to their parents. Participant Six maintained that using telephone interpreters, beside reducing misunderstandings, meant that Police valued hearing what the clients had to say. Another participant maintained that Police under-utilise the service. Consistent utilisation would protect children from negative impacts, demonstrate value, respect, and understanding. Through exploring this topic, it was also suggested that sensitive or complex situations warranted going further by engaging an interpreter in person to reduce misunderstandings and inaccuracies.

\section{Culture and Religion}

The change from Middle Eastern to western society instigates? challenges. Syrian refugees who are also Muslim, have greater difficulty, and particularly women. ${ }^{44}$ The find- 
ings from this study highlight that by seeking a greater understanding of how culture and religion influence the behaviour and responses of Syrian refugees in Wellington, opportunities to improve Police-Syrian interactions can be identified.

Female Syrian refugees experience difficulties in relation to their hijab when Police are involved. One referred to the male of the house blocking Police entry, while his wife dressed in her hijab, and another where a Syrian female was upset due to an intruder on the property seeing her without her head covering. Increased cultural understanding can ensure a Police response, which incorporates patience and empathy. The use of female officers can facilitate female victim cooperation in any investigation without the undue influence of gender based cultural concerns.

Traditional gender roles add more challenges for both Syrian Refugees and the New Zealand Police. Females wishing to wait to have their husbands present during reporting or statements can cause delays. This is understandable, however could lead to frustrations regarding the ability to solve crimes, or inaccuracies if females allow the male to speak for them or are influenced by their presence. Many of the Syrian refugee community are conservative Muslims. Participants spoke about how the traditional role of males provided control of many decisions and movements of females outside of the family home. This would inhibit the reporting of offending from within families, but also by those in the community. Participant One stated the broader concept of Domestic Violence, including psychological, emotional and financial abuse is not understood initially.

Making the decision to report Domestic Violence was particularly difficult for Syrian refugees. Participant Two described the experience in terms of leaving everything they know.

I feel, part of the reason why they don't want to go to the Police is because once they go to the Police they will be in the "white, kiwi, perspective." All their culture will be disgraced, and all their religion will not be honoured. They will have to go out of everything, their culture, their religion, their community, to reach for the police.

Demonstrating increased cultural understanding and sensitivity was identified as one way to address the fear of reporting, utilising avenues such as printed documents in Arabic, programs or counsellors where needed. There is evidence of adaptability and cultural considerations in the way some officers approach family harm. Participant Five noted that they had recently dealt with a Domestic Violence incident where the adult offender was interviewed with his parents present. This modification was beneficial in obtaining the truth of the matter. Wider application of this type of approach, aided by cultural understanding may increase both a willingness to report, as well as a more sensitive process for those of Syrian backgrounds. 
The circumstances which see females spending more time in the family home, combined with language challenges, may inhibit access to services and information, and lengthen resettlement times. This reflects similar findings by Fitzgerald regarding the way gender roles can contribute to social isolation of refugee females. ${ }^{45}$ Opportunities identified for women around driver licence training could support increased interaction outside the home. Participant Three spoke about the ability to drive providing the opportunity for women to shop for groceries, take children to school, and meet with friends.

\section{Refugee Background}

The Syrian community in Wellington comes from a predominantly refugee background and are largely Muslim. One participant remarked that there were around 250 Syrian families settled in Wellington District over the last five years. The general opinion was that connections in the community were strongest within their own localities.

Understanding how Syrian refugees identify themselves may help to further define challenges, or ways to approach opportunities. Wide-ranging backgrounds in education, rural and urban living, conservatism and religion all make for a complex and layered mix of people. Experiencing war and displacement add further intricacies to identity. Participant Three highlights a tendency to ignore this diversity:

People want them to be a homogenous group, and sort of want them to be one size fits all, but they are not.

The experience of becoming a refugee can greatly influence an individual's mindset. Participants Two and Six both spoke about the determination of refugees to get what they desire and how this thinking was a core instinct now. As Participant Two describes it,

The refugee from the definition is a person who came to a line that said "please don't cross" and they went across it, to be safe. If they obeyed those rules, they would be dead, bombed, kidnapped, etc. Having that process in the background - if they (an authority figure) say they can't and they (refugees) just say ok, that agreeing means they will never get it.

This thinking is reflected in an experience described by Participant Six, supporting a family on the emergency housing transfer list who were unhappy with waitlist times, and the resulting demand for Police resources where issues were more appropriately sitting with other organisations. Half the participants also referred to community information channels providing advice regarding situations and services. Consistent messaging, education regarding roles, patience and a coordinated approach across stakeholders may be necessary to address these challenges. 
Participant Two and Three spoke about how different transition country experiences influenced the mind-set of the Syrian Refugee cohorts settled across Wellington. Transitioning through Lebanon could have produced more negative experiences than countries such as Egypt. Syria's historic invasion of Lebanon and then the more recent war in Syria, which forced over one million Syrians to seek refugee status in Lebanon, led to an environment that was not welcoming, involving discrimination, curfews, and a lack of access to school and services. Participant Two surmised that this has caused a victim mind-set to develop in some Syrian refugees, which can be further utilised as a reason for not following the rules. Participant One further explained that Syrian refugees need to understand not just the rights, but the obligations involved in a democracy.

Obtaining the right approach, rested partly on the education of Community Police alongside earlier involvement in resettlement, providing non-crime opportunities to show visibility and increase engagement with refugees. This may also present Police more as individuals rather than intimidating authority figures or a "tool" to be utilised. Setting consistent expectations for Police-Community interactions across Wellington District, and ideally at a national level would ensure the right messaging is spread and assist in the management of particularly determined clients.

Youth

All participants identified the successful integration of youth as an area of current and future risk. Participant Five highlights the crossroads of this new group of migrant youth as the most pressing issue right now, stating that:

The first generation is a big indicator of where future generations will go.

The complexities experienced by refugee and migrant youth in negotiating identity in a cross-cultural setting are well documented. ${ }^{46}$ New Zealand studies highlight the concerns of Muslim parents regarding the influence of Western culture on their children. ${ }^{47}$ Participant Five, one of the Police participants, believed that the issues regarding Syrian youth would have their roots in the concept of identity, feelings of acceptance and belonging. Participants spoke about the particular freedom enjoyed by boys which may result in greater exposure to elements of New Zealand culture that cause conflict with their Muslim faith.

Research in New Zealand has not identified the routine profiling of ethnic youth by Police, however has found evidence that some ethnic youth may experience encounters with Police that they perceive as resulting from age and ethnicity characteristics. ${ }^{48}$ Thoughts around profiling were volunteered by two participants. Participant One had knowledge of Syrian youth dealt with by Police in drink driving situations. The shame experienced had in some cases led to boys attempting to deflect attention by suggesting profiling by Police led to the traffic stop. There was a risk that uneducated parents with very little English, the sons' control of information, and the high levels of trust between 
parents and children would allow this impression to take root. Community information channels could impact on the wider perception of Police. Participant Five spoke of how Ethnic Liaison Officers regularly facilitate explanations of Police processes to these families.

In contrast, Participant Three's impression was that Police regularly targeted poorer areas, and young male drivers of different ethnicity. While they believed young men were likely the biggest offenders for driving offences, targeting them pulled them into a cycle leading to the criminal justice system. This is similar to opinions expressed by ethnic minority participants of other New Zealand studies. ${ }^{49}$ Jaegar and Vitalis, found in 2005 that New Zealand Police staff from ethnic communities maintained that a paradigm shift was being experienced within the organisation with changes in policy and recruitment to target institutional racism. ${ }^{50}$ This suggests that while individual experiences cannot be discounted, the organisation supports the eradication of bias and prejudice in Police-ethnic community interactions.

Home country and outside influences should not be discounted in the creation of perceptions.

Not only do the police stereotype minorities, minorities stereotype the police. People tend to communicate stereotypical information and to embrace a stereotype of other groups. ${ }^{51}$

Stereotypes work both ways, therefore opinions should be interpreted with caution, particularly around contentious topics. Non-crime interactions could allow for demystification of Police operations. Participant Four stated that relationships between youth and individual officers permitted Syrian youth to seek advice. This creates trust and provides an avenue through which questions can be raised regarding negative experiences. This finding supports literature by Ho et al who note that migrants and refugees need to know not only "how" police systems work in New Zealand, but also "why."52

The closeness of Syrian family units suggests a potential for changes in the way information is shared and understood, when incidents take place, which is more sympathetic to Syrian cultural and family constructs. Kate et al recommend greater inclusion of alternative resolutions within justice pathways. ${ }^{53}$ The use of Te Pae Oranga Panels, ${ }^{54}$ for example, have been found to be effective in reducing the harm which can come from re-offending, ${ }^{55}$ and may provide pathways for dealing with offending that are more supportive of cultural sensitivities and solutions. Ethnic minority representation and perspectives in panels should be considered.

Positive interactions within the school system provide opportunities to build trust and connections with youth and their families from the outset. A school established in Porirua to deliver language and culture to Arabic children was suggested as an avenue 
for interactions. Sport was described as a positive avenue for the integration of youth across most participants and also emphasised in a youth report produced by New Zealand Refugee Resettlement Services in 2014. ${ }^{56}$ The opportunities for the involvement of Community Policing Services in this area are numerous.

\section{Perception of New Zealand Police}

Refugee support workers all believed that the Syrian refugee community viewed the New Zealand Police as the traditional "Crime Fighter" who conducts policing through arrests. ${ }^{57}$ Words such as "enforcement" and "law and order" were used to describe the role, with expectations that offenders would end up in jail. A lack of resolution, or delays in Police responses were thought to contribute to feelings of frustration, a perceived lack of care or low expectations and reduce the willingness to call again. Similar findings by $\mathrm{Ho}$ et $\mathrm{al}^{58}$ reinforce the notion that refugees and other ethnic minorities need to feel listened to, and that taking time to explain how and why, may mitigate negative impressions. Positive experiences with Police related to officer friendliness, and the response in the aftermath of the Christchurch Mosque Tragedy.

The perception of the Police as merely an enforcement service is potentially damaging, if police responses are not meeting expectations. Participant Two described the relationship between safety and trust in the following way:

This is also had a little bit of, not feeling faith in the Police protection system, and how they can feel safe. It's very related. If you are not feeling safe, then you will blame the Police, and if you do not trust the Police, then you will not feel safe. It's kind of like a circle of feedback.

This reference highlights the importance of education regarding systems and processes. Managing expectations from the outset will reduce misunderstandings and the erosion of trust from this community. Furthermore, encouraging greater ownership by individuals, emphasises the responsibility of both the Police and the community for creating safety in neighbourhoods. ${ }^{59}$

The perception of the Police as a "tool" for justice could inhibit relationship building with the community and true collaboration. Many participants remarked on the need for Police to be seen as human. Exposure to Police out of uniform, the engagement of officers in community groups and activities were described as important for building personal connections which allow the public to see beyond the uniform. This signals an opportunity for greater involvement of Community Police to participate in activities that fit within their role and address these issues. 


\section{Perceptions of Community Police}

Refugee support workers all believed that the Syrian refugee community lacked knowledge about Community Police and how they were any different from normal Police officers. Community policing is not understood from home and transition country experiences. Participant Two suggested the homogeny in uniform of the New Zealand Police made it difficult to perceive the differences in Police roles. The presence of Police in schools was known but not specifically as a Community Policing role. Even the refugee support workers from migrant backgrounds had difficulty recognising this.

Visibility by Community Police, and publicity within the community will create opportunities for engagement. Non-crime contact by Police can positively impact on relationships by increasing accessibility to hear concerns. Participants felt that meaningful consultation and efforts to understand their views showed Police cared about them. Participant Three identified the need for a professional and unbiased police service that supports and values diversity in order to maintain policing by consent:

The community will listen as much as they believe you are uncorrupted, unbiased, no different racism or discrimination happening, and that you understand their diversity. The more you have that, the more you will have people that will obey you without the need for having a police officer in front of everyone's house.

Given the traumatic and damaging authority experiences that refugees may have had, Syrian refugees can take significantly longer to feel the same confidence in the New Zealand Police than many other migrants.

Community policing involvement in the initial resettlement of refugees may improve engagement and integration experiences. Follow up in English Language classes could provide access to refugees to build initial relationships, support better availability and opportunity to educate about police services. This could also provide a platform to share written information in different languages.

\section{Meaningful Consultation}

Specific considerations for relationship development were identified. Meaningful consultation was essential to ensuring the needs of the Syrian community were understood and addressed. Participant Five considered that Police and ethnic communities will often have very different ideas regarding what is a problem. Failure to listen can result in wasted effort and resources. A case in point relates to Fitzgerald's identification of the disconnection between initiatives desired by Syrian refugees compared to those provided by support services. ${ }^{60}$ It may be possible to negotiate outcomes that support the aims and desires of both the Syrian refugee community and New Zealand Police. Par- 
ticipants identified drivers licence training as a potential opportunity for members of the Syrian community. While women could benefit from support in this area, cultural or family dynamics may influence the receptivity of this opportunity. There is a need to recognise the equality of opportunity that New Zealand can provide, and partner in a way that is sensitive to the cultural needs of a community, yet still allows individuals to utilise the opportunities provided.

Issues identified within communities may not sit within the power or influence of the New Zealand Police, as reported by Participant Five:

Knowing our limits, that it not always - it's hardly ever a Police issue. It's a social, economic, mental health.

Strong relationships across government services will ensure where cross over exists, concerns can be heard and understood through a lens that considers culture or background within any solutions identified. One of the aims of The New Zealand Police Ethnic Strategy is to:

Encourage a greater responsiveness to ethnic communities from social sector partners so that Police work is better supported by appropriate services. ${ }^{61}$

While this shows a commitment to improving the response to ethnic communities, findings suggest this strategy has not filtered down to those at the coal-face of policing. Only one of the Police participants spoken to were aware of the existence of a strategy to support ethnic communities, and it did not play a large part in their day- to-day operations. Participants recommended that consistency in approaches and agreements between services at a national level would be beneficial to ensuring expectations were well managed. This suggests that if these agreements do exist, they have not produced guidelines in the operational environment. Echoing the conclusions of BenPorat regarding Canadian research, the gap from strategy to operations that has been identified indicates that to achieve success, Police management need to be more than just intellectually committed. ${ }^{62}$

\section{Managing Expectations}

Managing expectations was a significant consideration identified by a number of participants. This reflects similar findings by Kadri in terms of the gap between expectations and service delivery for refugees regarding housing and employment services. ${ }^{63}$ The solvability of crime, potential justice outcomes, limited resources and support or influence with services outside of the Police role are just some of the ways in which these expectations were found to manifest. Some outlooks could come about due to a lack of knowledge, such as a lack of distinction between the Ministry of Justice, 
and the New Zealand Police. Education sessions, and the publication of information in Arabic are avenues through which information flow to the Syrian community could support clearer expectations.

The desire for Police to influence the processes of other government services was reported by half the participants. While Community Police regularly front a broad range of concerns from communities where the responsibility lies elsewhere, ${ }^{64}$ the influence of community information, combined with a refugee mind-set born out of trauma or transition country experiences may produce a determination to undertake a certain approach. Participant Six described their experience and response in the following way:

If they have an issue with housing - they come to Police. It they have an issue with whatever - they come to Police, and we have got to say to them, look it's not all us, but you have still got to do it in a supportive way and make sure they know who to contact.

Cultural and background understanding, consistent messaging, and an interagency approach may be beneficial for managing unrealistic expectations. Collaboration with partners can clarify roles and abilities of different government services, supporting positive community outcomes. Participant Six also argued for greater Community Police involvement to set expectations with Syrian refugees in the initial resettlement process. Clear communication and realistic commitment would ensure that any undertakings were sustainable, and relationships were underscored by trust and reliability. Participants Four and Five highlighted a tendency on the part of the New Zealand Police to begin projects and do really well, then shift resources into another area. Caution needed to be exercised regarding commitment as the spread of community information may significantly influence demand on Police resources and time.

Changes in police staff and resources can negatively impact on trust relationships with communities. Most community policing staff were well established, however staff turnover was identified as an increasingly common occurrence. Participant Five maintained that ethnic communities' wish to deal with the same person, and stability over a couple of years was necessary. Consistency in what relationships entail, smooth handovers, or a small team approach to relationship holding may provide solutions. Visibility at social and community gatherings, would demonstrate a genuine interest in the community, and the value placed on the relationship, which supports findings by Heyer regarding Ethnic Liaison Officer's nationally. ${ }^{65}$ Significant informal interactions between Police and the community have been promoted in Community Policing literature as essential to the development of trust and working relationships. ${ }^{66}$ 


\section{New Zealand Community Police Perceptions}

Community Police participants were passionate and engaged in the work they did. However they identified a serious need for cultural training and refugee background knowledge. Participant Six explained that this would assist in understanding why they may have behaved in a certain way and ensure the right support. Across all Police participants it was maintained that any knowledge gained was currently self-sourced, signalling a significant gap in their needs.

Participants did identify that cultural understanding of Maori and some Pacific cultures was provided but they were not aware of anything supporting other ethnicities. Not only was lack of cultural training acknowledged, but also a noteworthy lack of formal training for Community Policing. This absence has been previously identified in research by Heyer in his exploration of the role of New Zealand Police Cultural Liaison Officers. ${ }^{67}$ Reasons identified for the gap were the changing managerial staff, a lack of skilled practitioners for delivery, competing resources, and failure to prioritise Community Policing. Training gaps can lead to inconsistencies in the delivery of Community Policing services, creating differences between expectations and delivery.

The different Community Policing roles had connection but would be enhanced by more combined approaches. The singular position of Ethnic Liaison Officer for Wellington District Police revealed a difficulty in realistic support of all ethnic communities with the exception of Maori and Pacific people who had specific liaison officers. Partnerships were strategic and support for individual and community issues necessitated a consultative role. As New Zealand's refugee and migrant population grow, so too does the potential demand on this position. The development of local area Police champions was proposed as a stop-gap, to maintain an Ethnic Liaison portfolio for different communities, with support and some training provided by Maori, Pacific and Ethnic Services. While this idea had been promoted to local policing areas, it was not yet supported.

Police participants all described Community Policing in terms of building trust and confidence, with a geographic-based responsibility for relationship building and problem solving seen as the traditional concept of Community Policing. Time in the role was seen as beneficial to supporting communities. Self-direction, discretion to utilise alternative ways of resolving issues, and a holistic approach were essential to the various roles in Community Policing. Community Policing support to the Syrian refugee community had strong themes relating to education, follow up support during or after front line police attendance, facilitating integration, and relationship building characterised by consistency, genuineness and listening. Participant Five observed that improvements to ethnic or refugee community relationships in each area were often down 
to individual officers taking initiative. Raising the profile of Community Police, both internally, as well as within the different communities through good news stories were highlighted as an opportunity worth pursuing from a number of participants.

Most of the police participants reported they had a good relationship with the Syrian community in Wellington district. Refugee support workers also felt that in general, the Syrian refugee community viewed the New Zealand Police in a positive light. The New Zealand Police response to the Christchurch Mosque Tragedy was seen as instrumental for improving relations with the Muslim community.

Despite current positive perceptions of the Police-Syrian relationship, improvements are necessary to avoid negative impacts on trust and confidence in Police, such as under-reporting of crime and less calls for service. Participants referenced the potential emergence of a "them and us" society, signalling divisions between different ethnicities, which one participant believed would then be passed on to children. Participant Two warned of the snowball effect that could take place if issues weren't addressed, emphasising Police as a piece of this puzzle, and New Zealand being ideally positioned to ensure Syrian refugees were well-integrated from the very beginning.

\section{Conclusion}

This study identified challenges experienced by the Syrian refugee community, their perceptions of the New Zealand Police, and their experiences of crime. Opportunities are identified that could have a significant impact on improving the lived experiences of Syrian refugees in Wellington district. This study gained contrasting perspectives through the insights of Community Police interactions with Syrian refugees, identifying areas of risk, and methods to minimise this risk.

The findings recognise that aspects of communication, culture, refugee journeys, gender and youth contribute to the challenges experienced by the Syrian refugee community in Wellington district when interacting with the New Zealand Police. These features influence the way in which the Syrian refugee community perceive the Police and access services when in need. Utilising tools such as interpreters in the right situations demonstrates value and mitigates the risk to English speaking children. Understanding the impact of gender roles and utilising the best form of communication will ensure an efficient response which is culture-sensitive. The unique mind-set produced through the refugee journey can create challenges for services to address the needs of some refugees. The New Zealand Police is only one component of a refugee's integration journey. A clear understanding of the roles of partners and collaboration across services will ensure a consistent response, avoiding unrealistic expectations that can undermine trust and create perceptions of bias. 
Particular opportunities exist for Community Police to improve understanding and access to Police services, develop initiatives to support Syrian women and improve engagement with Syrian youth. Greater access to relevant information and services in native languages would empower members and communities with the means and opportunity to accept more responsibility for improving their own situations. Including ethnic community leaders within the alternative resolution pathways of the New Zealand Police could provide a bridge across cultures, demonstrating a responsiveness to multiculturalism, and supporting systems which are sympathetic to traditional nonwestern cultures.

Support from Police management needs to be demonstrated in the operational environment. Greater investment in cultural and refugee background training for Community Police is needed to facilitate genuine engagement and visibility in noncrime settings. Meaningful consultation and sincere relationships provide a platform to identify opportunities that the Syrian refugee community feel are needed, as opposed to Police assessments of needs. Involvement with the Syrian refugee community during initial resettlement would enhance the opportunities for engagement and education from an earlier stage. As a recent migrant community, New Zealand is in an optimal position to address challenges and opportunities when they first emerge, positively impacting on the experiences of crime and safety for this group of people.

The exploratory nature of this study leaves room for further research, on both sides of this topic. Understanding if the perceptions of refugee support workers are reflective of the Syrian refugee community themselves will provide further definition of challenges and opportunities. The application and analysis of Community Policing initiatives with the Syrian refugee community would enhance the identification and understanding regarding what constitutes successful outcomes. 
1 New Zealand Immigration. "Refugee and Protection Unit: Statistics Pack," Current to September 2020. Accessed 28 October 2020. https://www.immigration.govt.nz/documents/statistics/statistics-refugee-and-protection.pdf.

2 "Under Pressure, New Zealand Ends a Refugee Policy Branded Racist," New York Times, 4 October 2019. Retrieved from https://www.nytimes.com/2019/10/04/world/asia/jacinda-ardern-refugees-new-zealand.html.

3 John Battersby, Rhys Ball \& Nick Nelson, "New Zealand's Counter-Terrorism Strategy: A Critical Assessment," National Security Journal, p.88.

4 RASNZ Refugee Health and Wellbeing. "New Zealanders' Perceptions of Refugees," (April 2020): 22. Accessed 17 June 2020. https://rasnz.co.nz/wp-content/uploads/2020/06/New-Zealanders-Perceptions-of-Refugees.pdf

5 Hawa Kusuma Setawati Fitzgerald, "Ngā wāhine kaha from Syria: The experience of former refugee women from Syria resettling in Aotearoa New Zealand," (PhD Diss., Victoria University of Wellington, 2017): 71, 88. Accessed 12 August 2020. http://hdl.handle.net/10063/6874.

6 Fitzgerald, "Ngā wāhine kaha," 70.

7 Rose Joudi Kadri, "Resettling the Unsettled: The Refugee Journey of Arab Muslims to New Zealand," (PhD Diss., Auckland University of Technology, 2009): 169. https://openrepository.aut.ac.nz/ bitstream/handle/10292/988/JoudiKadriR.pdf?sequence=3; Ruth DeSouza, "Doing it for ourselves and our children - Refugee Women on their own in New Zealand," (Report, Auckland University of Technology, 2011): 12. Accessed 6 September 2020. http://www.ruthdesouza.com/wp-content/uploads/2011/06/ DeSouza-Doing-It-for-Ourselves-full.pdf; S Elliot \& I Yusuf, "Yes, we can; but together": Social capital and refugee resettlement," Kotuitui: New Zealand Journal of Social Sciences Online 9, no.2 (2014): 106, https://doi.org/10.1080/1177083X.2014.951662.

8 Kadri, "Resettling the Unsettled," 248.

9 Kadri, "Resettling the Unsettled," 156-157.

10 Elliot \& Yusuf, "Yes, we can," 105-106.

11 Elliot \& Yusuf, "Yes, we can," 107.

12 Kate Anet, Jane Verbitsy and Kaden Wilson, "In Different Voices: Auckland Refugee Communities' Engagement with Conflict Resolution in New Zealand," Journal of International Migration and Integration, 20 (2019): 469, https://doi.org/10.1007/s12134-018-0619-4.

13 Kate, Verbitsky and Wilson, "In Different Voices," 473.

14 Kate, Verbitsky and Wilson, "In Different Voices," 469.

15 Kate, Verbitsky and Wilson, "In Different Voices," 473.

16 Kate, Verbitsky and Wilson, "In Different Voices," 473.

17 Kate, Verbitsky and Wilson, "In Different Voices," 474.

18 Sabina Jaegar and Tony Vitalis, "Ethnic Diversity in the New Zealand Police: Staff Perspectives," Equal Opportunities International 24, no. 1, (January 2005): 20. https://doi.org/10.1108/ 02610150510787926

19 Jaegar and Vitalis, "Ethnic Diversity," 22.

20 Elsie, S. Ho, Jenine Cooper and Bettina Rauschmayr. Ethnic Community Perceptions of the New Zealand Police. A Report prepared for the New Zealand Police (University of Waikato, 2006): 13-14. Accessed 26 April 2020. http://www.police.govt.nz/about-us/publication/ethnic-community-perceptions-new-zealand-police.

21 Sameer Nisar, "South Asian immigrants' perceptions of the New Zealand Police: An exploratory study," (Auckland University Technology, 2013): 64. Accessed 12 August 2020. https://openrepository. aut.ac.nz/handle/10292/5531; Kate, Verbitsky and Wilson, "In Different Voices," 469.

22 Ho, Cooper and Rauschmayer, Ethnic Community Perceptions, 11, 18.

23 Eileen Pittaway, Chrisanta Muli and Sarah Sheiter, "I Have a Voice- Hear Me! Findings of an Australian Study Examining the Resettlement and Integration Experience of Refugees and Migrants from the Horn of Africa in Australia." Refuge: Canada's Journal on Refugees 26, no. 2 (2009): 141. Accessed 7 April 2020. http://search.ebscohost.com/login.aspx?direct=true \&db=edselc\&AN=edselc.2-52.0-79 958861652\&site=eds-live\&scope=site141; Douglas Sharp and Susie Atherton, "To Serve and Protect? The Experiences of Policing in the Community of Young People from Black and Other Ethnic Minority Groups", British Journal of Criminology, 47 (June, 2007), 753. https://doi.org/10.1093/bjc/azm024. 
24 Camille Nakhid. "Police encounters with African youth in New Zealand - the impact on the youth, family, and community." Safer Communities, 16, no. 2 (2017): 68. https://doi.org/10.1108/SC-01-20170001; Nisar, "South Asian Immigrants' perceptions," 53, 73.

25 Ho, Cooper and Rauschmayer, Ethnic Community Perceptions, 16; Nisar "South Asian Immigrants' perceptions," 53; Nakhid, Camille, "Police encounters with African,"68.

26 Ho, Cooper and Rauschmayer, Ethnic Community Perceptions, 15-16.

27 Ho, Cooper and Rauschmayer, Ethnic Community Perceptions, 16.

28 Ho, Cooper and Rauschmayer, Ethnic Community Perceptions, 15-16; Nisar,"South Asian immigrants' perceptions," 61; Kate, Verbitsky and Wilson. "In Different Voices," 469.

29 Ho, Cooper and Rauschmayer, Ethnic Community Perceptions, 16.

30 Guy Ben-Porat, "Policing multicultural states: lessons from the Canadian model." Policing \& Society, 18, no. 4 (2008): 411. https://doi.org/10.1080/10439460802094686.

31 Ben-Porat, "Policing multicultural states," 421-422.

32 Parastou Saberi, "Toronto and the "Paris Problem": Community policing in "immigrant neighbourhoods", Race \& Class, 59, no. 2 (2017), 54-55, 57-58, https://doi.org/10.1177/0306396817717892.

33 Sulaimon Giwa, "Community policing in racialized communities: A potential role for police social work," Journal of Human Behaviour in the Social Environment, 28, no. 6 (2018): 719. https://doi.org/10. 1080/10911359.2018.1456998.

34 Giwa, "Community policing in racialized," 721-722.

35 Stephen D. Mastrofski, "Critic: Community Policing: A Skeptical View," in Police Innovation: Contrasting Perspectives, $2^{\text {nd }}$ Edition, eds. David Weisburd and Anthony A. Braga (Cambridge: Cambridge University Press, 2019), 51.

36 Ben-Porat, "Policing multicultural states," 422-423.

37 Wesley G. Skogan, “Advocate: Community Policing," in Police Innovation: Contrasting Perspectives, $2^{\text {nd }}$ Edition, eds. David Weisburd and Anthony Braga (Cambridge: Cambridge University Press, 2019), 30-31.

38 Garth den Heyer, "New Zealand Police Cultural Liaison Officers: Their Role in Crime Prevention and Community Policing," in Policing and Minority Communities, eds. James F. Albrecht, Garth den Heyer, and Perry Stanislas (Cham, Switzerland: Springer, 2019), 249-250, https://doi.org/10.1007/978-3030-19182-5.

39 The audio recordings were kept for 3 months, should the participants wish to review their recordings and add, or change anything they said. After this only the transcriptions were available.

40 Ho, Cooper and Rauschmayr, "Ethnic Community Perceptions," 13-14.

41 Ho, Cooper and Rauschmayr, "Ethnic Community Perceptions," 14.

42 New Zealand Red Cross. "Refugee Youth Resettlement Report. 'Then Came the Reality': Lived experiences of Refugee Youth in their first 12 months in New Zealand," (May 2014): 25. Accessed 8 June 2020 from https://redcross.org.nz/about-us/publications.

43 Ho, Cooper and Rauschmayr, Ethnic Community Perceptions, 14.

44 Fitzgerald, "Ngā wāhine kaha," 71; DeSouza, "Doing it for ourselves," 9.

45 Fitzgerald, "Ngā wāhine kaha," 88.

46 Kate, Verbitsky and Wilson, "In Different Voices," 468.

47 Kate, Verbitsky and Wilson, "In Different Voices," 468; Kadri, "Resettling the Unsettled," 163;

DeSouza, "Doing it for ourselves," 5.

48 Nakhid, "Police encounters with African," 68.

49 Nisar, "South Asian immigrants' perceptions," 68; Ho, Cooper and Rauschmayr, Ethnic Community Perceptions, 15.

50 Jaegar and Vitalis, "Ethnic Diversity," 18.

51 Palmiotto, Community Policing, 142.

52 Ho, Cooper and Wilson, Ethnic Community Perceptions, 21.

53 Kate, Verbitsky and Wilson, "In Different Voices," 473. 
54 Te Pae Oranga Panels are a New Zealand Police and Maori initiative which utilises a Maori Community Panel to address low level offending as an alternative to the court-based adversarial justice system historically utilised.

55 Darren Walton, Samara Martin and Judy Li. "Iwi community justice panels reduce harm from re-offending," Kotuitui: New Zealand Journal of Social Sciences Online, 15, no. 1 (2020): 90. https://doi.org/ 10.1080/1177083X.2019.1642921.

56 New Zealand Red Cross. "Refugee Youth Resettlement Report," 21.

57 Steven P. Lab, Crime Prevention: Approaches, Practices and Evaluations, 9th ed., (New York: Routledge, 2016), 245.

58 Ho, Cooper and Rauschmayer, Ethnic Community Perceptions, 16.

59 Skogan, "Community Policing," 29.

60 Fitzgerald, "Ngā wāhine kaha," 99.

61 New Zealand Police. "Working Together with Ethnic Communities - the Future: Police Ethnic Strategy," Accessed 26 April 2020. https://www.police.govt.nz/about-us/publication/working-together-ethnic-communities-future.

62 Ben-Porat, "Policing multicultural states," 421-422.

63 Kadri, "Resettling the Unsettled," 156-157.

64 Skogan, "Community Policing," 31.

65 Heyer, "New Zealand Police," 249.

66 Skogan, "Community Policing," 29.

67 Heyer, "New Zealand Police," 249. 